\title{
Teaching mediation skills at technology-enhanced ESP classes at technical universities
}

\author{
Yuliana Lavrysh - Nataliia Saienko
}

DOI: 10.18355/XL.2020.13.04.02

\begin{abstract}
Mediation is a new trend in the language teaching methodology that has been disregarded at English language classes at technical universities. While teaching ESP students is crucial to develop and improve their complex communicative competence, it should not be limited to reading, writing, listening, and speaking skills because reallife communication involves more sophisticated language skills such as mediation. Linguistic mediation is a dual-nature phenomenon with cognitive and linguistics domains. The present study demonstrates some practical recommendations on how to implement mediation teaching into ESP courses with the integration of online educational technologies. Our study was carried out among ESP teachers at a technical university and outlines the findings of an empirical study on teachers' perception of language mediation. Our evidence-based findings and personal experience confirm that mediation can enrich the ESP syllabus and bridge the gap between the university and real professional life.
\end{abstract}

Key words: mediation, educational technologies, ESP, language competence, fieldoriented communication

\section{Introduction}

The processes of international integration and globalization of the main spheres of society determine the need for specialists who act as intermediaries between their own and other professional cultures, carrying out the necessary mediation activities both in written and oral forms. Mediation, or the transmission of information through an intermediary, is becoming mainstream in the modern foreign language teaching methodology. The current level of international interaction of representatives of different professional communities indicates that knowledge of a foreign language is not always sufficient for foreign language professional communication. There is a growing need for professionals who can act as intermediaries between their own and other professional cultures, to carry out appropriate mediation activities in writing, as in the context of international integration of post-industrial society, the amount of professionally oriented information in writing in different languages increases.

Traditional strategies of English for Specific Purposes (ESP) teaching were previously constructed around four basic language skills: reading, speaking, writing, and listening. Nowadays, educational goals are set according to students' needs that impact the context of the educational process. Curricular should reflect the workplace language reality that goes beyond these four skills. Basic skills are still enough to process the text or information, but not enough to communicate it to representatives of other cultures, professions, or non-experts. Therefore, updated CEFR (2018) recommendations suggested four main dimensions of English language competence: reception, production, interaction, and mediation. The last dimension is focused on adapting the information, collaborating, explaining, synthesizing texts and ideas, managing successful interaction. The mediation skill is not completely new, but it has been transformed into a more extended and more interactive way of language, cultural, and social competence acquisition. So, this dimension can complement rather than replace the course goals. Mediation is a crucial skill that combines language 
competence and "soft" skills for meaningful information communication (Lavrysh, 2016).

In order to interact effectively in society, it is necessary to introduce mediation skills training at all levels of education. In the field of theory and study of foreign languages, mediation is understood as the interaction between social agents, who, for some reason, cannot communicate directly and co-construct the meaning during the interaction. Skills of mediation include interpretation of concepts, paraphrases, summary, report, a retelling of the information, generalization of information, recording information to transfer it to another participant of interaction, annotation, abstracting. All these examples of mediation can be carried out in the context of professional or personal communication. Mediation also can be regarded as a cognitive skill because it deals with paraphrasing skills, changes in the style and level of complexity of the language depending on the needs of the interlocutor or audience, explanations through examples or generalizations. For the specialists in the field of foreign language teaching, it means that the task is to develop a special component of discursive (speech) competence, namely: language and extra-linguistic skills and ways of working in language mediation, which form the meditative competence of the student.

The purpose of the study is to demonstrate the ways of teaching language mediation in the technology-enriched educational environment for students of engineering specialties. In order to obtain credible findings, the following questions were proposed:

1. How do teachers of ESP perceive mediation as an educational phenomenon?

2. What educational strategies and educational technologies are efficient in teaching mediation in ESP course?

\section{Theoretical background}

In linguistic research, mediation is considered as a special kind of discourse, as it is characterized by specific cognitive, communicative, and pragmatic strategies that are the driving force behind the main communicative task of mediation discourse - achieving an alternative solution that would reconcile the audience. In modern methodological literature, mediation is understood as translation, adapted to social needs in order to adjust mutual understanding between representatives of different cultures in acts of communication in various fields. The concept of mediation has been outlined in a variety of works by scholars such as Brown (2002), Azadi, Biria, Nasri (2018), Cheng (2011), Chovancova (2016), who consider mediation as a constituent of adult education which involves language learning as a part of formal and informal education. It should be noted that mediating involves not only verbal forms of communication (oral, written, or interactive) but also exclusively visual or paratextual (for example, drawings, graphs, charts, etc.). In addition, mediation can be multimedia or hybrid (Viaggio, 2000) and allows predicting of different sources of information: from the verbal text (oral or written), supplemented by video and audio text. Viaggio (2000) understands mediation as a creation of relevant identity between what the author wanted to convey and what the recipient understood. Due to the mediator's heuristic competence, he creates an optimally relevant series of speech acts, taking into account that in the presence of subjective and objective limitations typical for in any intercultural mediation, it is possible to obtain the mentioned above relevant identity.

According to Bayram (2008), training mediation should begin at a stage when students have already acquired a certain language competence level (but not lower than B1) and socio-cultural knowledge and skills. Such training is focused on the formation and development of special speech skills necessary for intercultural

XLinguae, Volume 13 Issue 4, October 2020, ISSN 1337-8384, eISSN 2453-711X 
communication. The modern explanation of mediation is at variance with previous concepts of language acquisition that separated the notions of the language itself and language use. Nowadays, language learning, ESP, in particular, is seen through social or professional content. Such perception of mediation contributes to the language identity construction process (Pavlenko, Lantolf, 2000). Howell (2017) notices that efficient mediation requires "interpersonal skills such as appropriate non-verbal communication (distance, gesture, touch, expression) and active listening using checks, confirmations, and clarifications" (Howell, 2017:149). The relevance of mediation to ESP students was argued by Hutanu and Jieanu (2019), who states that language mediation creates meaningful activities for competence- and task-based classes due to its complexity and real-life reflection.

North and Piccardo (2016) outline two types of linguistic mediation: interlinguistic (transforming one kind of text into another, interpreting skills in terms of two or more languages) and intralinquistic that can be performed in the target language (reporting, summarizing, explaining, clarifying). However, Lewis, Jones, Baker (2012) separate the mediation that is carried out in a multilingual environment. They explain that such kind of collaborative integration is more familiar to students who study a foreign language. Thus, the mediation skills are better developed in those students who know several foreign languages.

In the process of learning a foreign language, in particular, English, mediation, according to some researchers (North, Docherty, 2016; Peacock , 2009)

is demonstrated through the following forms:

1) non-interactive - transmission of information from the communicator to the recipient: a) translation; b) abstracting; c) annotation; d) review; e) retelling; f) summarizing.

2) Interactive - the communicator sends some information to the recipient in order to get a response from him. The mediator supports the interactive process by transmitting messages from the communicator to the recipient and then vice versa: a) consecutive translation; b) textualization of intentions; c) mediation in negotiations;

3) mixed-language mediation with elements of interaction between the mediator and one of the communicants (presentation of the collected information followed by discussion)

Experts who developed CEFR, highlight that mediation can be managed through three dimensions: mediating a text, mediating concepts, and mediating communication. Mediating a text means transferring the content of a text to someone who does not have access to it (CEFR 2018: 106-117). Mediating concepts refer to the process of facilitating access to knowledge and concepts to others, both from a relational and a cognitive point of view. Mediating communication outlines the process of facilitating understanding and communication by acting as a linguistic and cultural link between people. With a view of successful mediation teaching, CEFR (2018) guidelines suggest to us different mediation situations, which can be combined. In these activities, students:

- after reading a text, should produce a message with related content to another person who has no access to the first text;

- perform the role of a mediator in a face-to-face interaction between two interlocutors who do not understand one another for whatever reason;

- explain a cultural phenomenon to representatives of another culture;

- participate in a conversation or discussion that involves code-switching or changing the level of information complexity.

If we consider mediation as a learning activity, it should be assessed to demonstrate the students' academic dynamics. Scholars Coste and Cavalli (2015) carried out an empirical study to identify the descriptors of mediating activity verification and assessment. By means of these descriptors, teachers are able to 
develop mediation competence relevant to all types and contexts of language application.

The modern trends in education imply the integration of technologies into the process of teaching all subjects, language learning, and mediation as well are not an exception. Educational technology as a tool for mediation teaching is projected in Shapira's study (2016) where he indicates that technologies can serve as knowledge mediators when students read Wikipedia with brief information about a subject, perform online tests or MOOCs. Computer-assisted strategies suggest more opportunities to use mediation skills while communicating in terms of internationalization and globalization of all fields of human interaction and cooperation.

\section{Methodology}

The present study is based on an action qualitative research design framework (Creswell, 2005) that was used to obtain education practitioners' reflection and perceptions of linguistic mediation teaching enhanced with mobile learning from personal teaching practice. The key idea of the study was to describe the context, experience, challenges, and perspectives of the mediation enhancement to view this educational issue holistically. The action research framework was employed to provide evidence-based results of the study, and the active involvement of participants in the study added relevance and reliability to the quality of the results. The study procedure included some stages: initial questionnaire for teachers about their perception of the mediation as educational phenomena, the follow up three webinars sessions from the experts about the mediation nature and the ways of its integration into the teaching process, classes observations to support teachers' practice and to verify the learning outcomes, final self- reflective report and open discussion on the results of the experiment.

\section{Data collection and analysis tools}

In order to collect data, we used open-ended questionnaires provided through Google Forms, 2 lessons video-recording, and 4 observations with rubrics for the evaluation of mediation teaching quality and self-reflection reports to assess the level of skills development. These data collection tools displayed teachers' perception of such issues as mediation, mobile technologies, collaborative ways of teaching, mediation skills assessment. The questionnaire included the following questions:

1. What language skills does mediation belong to: reading, writing, listening, or speaking?

2. What is the idea of language mediation?

3. What mediation activities do you use?

4. What are the criteria for mediation skill assessment?

5. How often do you suggest students mediation activities?

6. Do you integrate mobile technologies and mediation activities? If yes, list some of technologies.

With a view of questionnaires and self-reflection reports data analysis, we employed content analysis to reach credible research findings. The questions for selfreflection reports were:

1. What have you known about the mediation?

2. What issues are still disputable for you?

3. How did you integrate the mobile technologies and mediation activities in your classes?

4. What benefits of mediation have you noticed?

XLinguae, Volume 13 Issue 4, October 2020, ISSN 1337-8384, eISSN 2453-711X 
5. What challenges did you encounter?

The teaching quality of classes with meditation integration was evaluated according to the observation rubric suggested by the experts. The observed teachers were informed that the observation goal was to support and to identify the students' reaction, successful ideas, and challenges rather than an evaluation of class management and academic performance. Classes with mediation activities correlated the curricular of the ESP and students' language level and social background. Participants were not limited in the choice of the students' course, group, or language level.

\section{Participants and research ethics}

The participants of the study were teachers of ESP $(n=50)$ from the Faculty of Linguistics National Technical University of Ukraine "Igor Sikorsky Kyiv Polytechnic Institute". Participants were selected randomly according to their personal wish to participate in the professional development study. Participants were with different teaching experience terms: 22 novice teachers (experience less than 3 years), teachers with experience from 3-10 years $(n=23)$, teachers with an experience more than 20 years $(n=5)$. Teachers gave their agreement on classes video-recording and results processing; questionnaires were anonymous. Teachers could discontinue their participation at any time of the study. Experts for webinars performance and class observations were invited from the center for English language teaching excellence. The study was designed and initiated by teachers of the Department of English for Engineering. The researchers of the study played the non-participant observer role (Creswell, 2005). The procedure of the study was approved by the Scientific Boards of the faculty of Linguistics.

\section{Results and Discussion}

The qualitative data collected from the questionnaire, self-reports, and class observations provided evidence on how mediation was perceived by teachers initially and the dynamic of meaningful transformations of the mediation integration. The questionnaire findings revealed that teachers $(86 \%)$ had little knowledge of mediation and ways of its integration into the educational process. Participants $(78 \%)$ mostly described the process of mediation between a teacher and students while the knowledge transition where a teacher performed the role of a mediator. Some of the participants $(44 \%)$ wrongly viewed the mediation as pure translation or retelling of texts, and they were not connected to ESP discourse. The majority of teachers (77\%) did not use educational technologies for mediation. However, $23 \%$ of teachers pointed out a few language technologies they used during the classes as for mediation, but in fact, mostly applied for grammar or vocabulary learning. The situation dramatically changed after the short course on mediation and personal experience of mediation teaching. The distribution of mediating activities used before the course on mediation integration is presented in Figure 1 and after the course -Figure 2 (10 points as the highest score of distribution). 
Distribution of mediation activities before the course

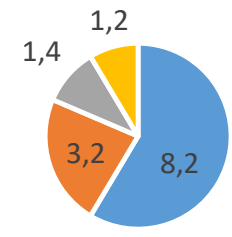

- translation of texts L1-L2 a retelling of texts

- texts summarizing $\quad$ news reporting

Figure 1: Pre-course activities distribution

\section{Mediation activities distribution after the course}

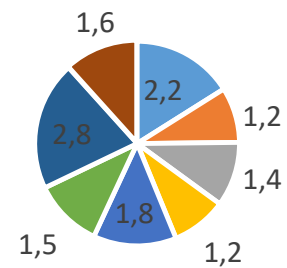

- translation of texts

- summarizing

- retelling

- reporting of specific information

- explaining visuals

- interpreting of field-related information

- adjusting language

- note taking

\section{Figure 2: After-course activities distribution}

Among more frequently used mediating activities that were suitable for our students and reflected their possible field-oriented situation, we employed clarifying or explaining activities (students of 1-2 courses) and breaking down complicated information, visually representing information and adjusting language (students of 3-4 courses). The key task was to change the professional discourse and to reduce the complexity of technical language. While transforming the texts, the student used a checklist that outlined the key strategies: 
- $\quad$ Are you using the technical terms of high professional level;

- Are these technical terms accessible to the reader, and do they align with the idea of the content;

- Have you provided some explanation to the mentioned terms;

- Do you use terms consistently, or do you include clarification or synonyms?

- Are you using simple language to reduce jargon and technical complexity as much as possible?

These changes were seen during class observation, and their context was connected to ESP. Experts also admitted that students' engagement increased as well as the type of communication transformed from mostly teacher- students (T-S) to student-student (S-S) interaction. This shift also promoted the changes in teaching modes of classes. Our study of ESP in terms of a mediation approach was conducted allows through two models of mediation training as it was suggested by Brown (2002), and adapted according to our needs. The first model was applied for students of 1-2 courses, and the mediation initiator and assessor was a teacher who promoted interactive activities without ESP context, encouraging students to interact with familiar topics mediating given texts without mediating self-constructed concepts. The second model for students of 3-4 courses was based on the fact that students, having mastered the necessary set of professional competencies and mediating skills, could become peer and collaborative mediators and mediate concepts and manage collaborative mediation during conferences, meetings, or workshops. Classes were mostly interactive, including round tables, web quests, brainstorming, cases, web conferencing, project assignments.

According to the systematic and progression principles of pedagogy, we view the process of mediation teaching as a system of closely correlated parts. The achievement of learning outcomes depended on the correlation of all elements and factors involved in the process. It means that the level of tasks complexity should be changed gradually; every previous task should be correlated with the following; thus, mediation teaching should be systemic; every outcome should be assessed and verified.

Therefore, following the mentioned principles, we developed a framework of exercises to teach mediation skills to students at technical universities. Bearing in mind that mediation activities are divided into three types (mediating a text, concept, and communication) (CEFR), we tried to distribute our exercises considering this classification.

Future engineers deal with lots of texts which provide the information about the specification, safety rules, manuals, description of process etc. Engineers have to process the information from the texts and mediate them to colleagues, clients, apprentice students, community. Thus, the key factor for successful mediation, that we teach students is to know the audience whom students will communicate with. It helps choose appropriate mediation communication strategies so the audience could completely comprehend the information. To understand the audience needs, we suggest students asking self-reflection questions:

- What do they know about the subjects?

- What do they need to know?

- How might they use the information?

After students find out the audience type, the next step is to identify the main idea of the text for mediating. We asked students to find keywords, topic sentences, conclusions that might express the main idea. We gave students short texts (500 words) for skimming, and the task was to tell the main idea in one sentence and confirm it with five keywords.

The next stage is to teach students linguistic strategies of mediation: paraphrasing, clarification, amplification, summarizing. We involved such activities as: replacing words and phrases with synonyms, sentence rearrangement, and 
transformations, putting information into a different order, avoiding description of extra details, etc. As mediation is of a dual-nature concept with linguistic and cognitive domains, the teaching of non-linguistic strategies is also very important because they help simplify the idea or concepts, predict possible points or misunderstanding, facilitate the interaction. However, we have to bear in mind that when we perform the assessment of mediating activity, we should assess both language and cognitive skills.

Regarding educational technologies integration into the mediation teaching, we suggest the following combinations:

- Youtube subtitles creation for language adjustment or specific information reporting;

- Google mind-mapping tools for information simplifying or concepts mediation;

- Flipgrid.com for oral texts summarizing, visuals description or explanation of concepts;

- Padlet.com for written translations, paraphrasing or clarifications;

- softo.org or onlineparaphrase.net for paraphrasing practice;

- online synonyms dictionaries for simplifications and clarification;

- MindMeister or MindMup for key words identification;

- AudioNote for rendering and audio recording of audio files summarizing or rendering;

- Classkick for peer assessment and collaborative work on mediating technical texts;

The contribution of technologies is hard to overestimate as among their educational benefits are: increased students' motivation and engagement through student-centered activities, visualization of information, interactivity, encourages collaboration (Hoven, Palalas, 2011); learning motivation enhancement due to mobile devices is supported by a range of studies (Baek, Guo, 2019). It is well-known that most part of teaching is instructional, but technologies make classes more emotional and creative that contributes to the development of 21st-century skills. Moreover, audio and video information bring authenticity into classes that, together with mediation bridge the gap between university and real life.

\section{Conclusion}

In this study, the aim was to assess teachers' experience on the issues of linguistic mediation teaching. According to the findings of the study, we can state that mediation is still a challenge for teachers, however, it is not a new educational concept and some activities imply the mediation teaching. Due to updated CEFR descriptors and guidelines, we have descriptors and activities examples, thus, it has become easier to develop mediation skills, especially integrating mediation and technologies. The present study has contributed towards enhancing our understanding of linguistic mediation teaching as these new skills are authentic and raise the language competence of students. Further research needs to be carried out in order to develop clear assessment criteria for such activities as language adjustment or relaying specific information.

\section{Bibliographic references}

AZADI, G. - BIRIA, R. - NASRI, M. 2018. Operationalising the Concept of Mediation in L2 Teacher Education. In: Journal of Language Teaching and Research, vol. 9, pp. 132-140. ISSN 1798-4769.

BAEK, E. - GUO, Q. 2019. Instructional Design Principles for Mobile Learning. In: Handbook of Mobile Teaching and Learning, eds. Yu (Aimee) Zhang, Dean Cristol: Springer, pp. 1-22. ISBN 978-981-13-2765-0.

BROWN, D. 2002. Mediated learning and foreign language acquisition. In: ASp, vol. 35, n. 36, pp. 167-182. ISSN 2108-6354.

XLinguae, Volume 13 Issue 4, October 2020, ISSN 1337-8384, eISSN 2453-711X 
BYRAM, M. 2008. Translation and Mediation - Objectives for Language Teaching. In: Cultures in translation, vol. 4, pp. 22-26. ISSN 2511-879X.

CHENG, X. 2011. Knowledge of mediation and its implementation among secondary school EFL teachers in China. In: Theory and Practice in Language Studies, vol. 1, n. 9, pp. 1111-1121. ISSN 1799-2591.

CHOVANCOVA, B. 2016. Mediation in legal English teaching. In: Studies in logic, grammar and rhetoric, vol. 45, n. 58, pp. 21-35. ISSN 0860-150X.

COSTE, D. - CAVALLI, M. 2015. Education, mobility, otherness: the mediation functions of schools. In: Strasbourg: Council of Europe DGII - Directorate General of Democracy, Language Policy Unit. Available online: http/www.coe.int/lang

Common European Framework of Reference for Languages. 2018. Companion volume with new descriptors. Cambridge University Press. ISBN: HB 0521803136

CRESWELL, J. W. 2005. Educational research: Planning, conducting, and evaluating quantitative and qualitative research (2nd ed.). NJ: Merrill Prentice Hall. ISBN-10: 013-136739-0.

HOVEN, D. - PALALAS, A. 2011. (Re)Conceptualizing Design Approaches for Mobile Language Learning. In: CALICO Journal, vol. 28, n. 3, pp. 699-720. ISSN: 0742-7778.

HOWELL, P. 2017. Cross-Language Mediation in Foreign Language Teaching. In: Hiroshima Studies in Language and Language Education, vol.20, pp. 147-155. ISSN: 1347-0892

HUTANU, M. - JIEANU, I. 2019. Mediation activities for teaching Romanian as a foreign language. In: Structure, use, and meaning. Language policies and practices in institutional settings, eds. Elena Buja and Stanca Măda: Editura Universității „Transilvania”, Brașov, pp. 173-188. ISBN 6061911416.

LEWIS, G. - JONES, B. - BAKER, C. 2012. Translanguaging: origins and development from school to street and beyond. In: Educational Research and Evaluation: An International Journal on Theory and Practice, vol.18, n. 7, pp. 641654. ISSN 1744-4187.

LAVRYSH, Y. 2016. Peer and self-assessment at ESP classes: case study. In: Advanced education, vol. 6, pp. 60-68. ISSN 2410-8286

NORTH, B. - PICCARDO, E. 2016. Developing illustrative descriptors of aspects of mediation for the CEFR. In: Language teaching, vol. 49, n. 3, pp. 455-459. ISSN 1475-3049.

NORTH, B. - DOCHERTY, C. 2016. Validating a set of CEFR illustrative descriptors for mediation. In: Cambridge English: research notes, vol. 63, pp. 24-33. ISSN 1756-509X.

PAVLENKO, A. - LANTOLF, J. 2000. Second language learning as participation and the (re)construction of selves. In: Sociocultural theory and second language learning, ed. J. Lantolf: Oxford University Press, pp. 155-178. ISBN: 9780194421607.

PEACOCK, M. 2009. The evaluation of foreign-language-teacher education programmes. In: Language Teaching Research, vol. 13, n. 3, pp. 259-278. ISSN: 1477-0954.

SHAPIRA, O. 2016 A Theory of Mediators' Ethics: Foundation, Rationale, and Application. Cambridge: CUP. ISBN 9781316534205.

VIAGGIO, S. 2000. The Overall Importance of the Hermeneutic Package in Teaching Mediated Interlingual Communication. In: The Interpreters' Newsletter, n. 10, pp. 129-145. ISSN 1591-4127.

Words: 4119

Characters: 28895 (16,10 standard pages) 
Yuliana Lavrysh, PhD, Assoc. Prof

Department of English for Engineering,

Faculty of Linguistics,

National Technical University of Ukraine "Igor Sikorsky Kyiv Polytechnic Institute"

Pobedy Av. 37

03056, Kyiv

Ukraine

lavrish.yuliana@11l.kpi.ua

Nataliia Saienko, PhD, Prof

Department of English for Engineering,

Faculty of Linguistics,

National Technical University of Ukraine "Igor Sikorsky Kyiv Polytechnic Institute"

Pobedy Av. 37

03056, Kyiv

Ukraine

saenko106@gmail.com 